\title{
Ética y Reflexividad: Experiencias Museológicas Comunitarias en México
}

Ethics and Reflexivity: Community Museum Experiences in Mexico

\section{Norma Angélica Ávila Meléndez}

\section{(2) OpenEdition \\ 1 Journals}

Edición electrónica

URL: http://journals.openedition.org/iss/378

DOI: $10.4000 /$ iss.378

ISSN: 2306-4161

Editor

ICOM - International Council of Museums

Edición impresa

Fecha de publicación: 1 diciembre 2015

Paginación: 25-36

ISSN: 2309-1290

\section{Referencia electrónica}

Norma Angélica Ávila Meléndez, «Ética y Reflexividad: Experiencias Museológicas Comunitarias en México », ICOFOM Study Series [En línea], 43b | 2015, Publicado el 06 febrero 2018, consultado el 05 mayo 2019. URL : http://journals.openedition.org/iss/378 ; DOI : 10.4000/iss.378 


\title{
Ética y Reflexividad Experiencias Museológicas Comunitarias en México
}

\author{
Norma Angélica Avila Meléndez \\ Instituto Nacional de Antropología e Historia - México
}

A la memoria del maestro Felipe Lacouture Fornelli

\section{Introducción}

El texto examina la dimensión ética de las experiencias museológicas que ha impulsado el Instituto Nacional de Antropología e Historia (INAH) en México desde el enfoque de la Nueva Museología, estos proyectos plantearon una expansión de la idea del museo, definido en la Mesa de Santiago de Chile como un acto pedagógico para el ecodesarrollo (Lacouture, 1989).

Si bien estas experiencias reivindican los postulados de la Nueva Museología, es pertinente aclarar que presentan profundas diferencias conceptuales y metodológicas entre ellas, sus genealogías no son lineales ni comparten la misma visión sobre los alcances políticos de su praxis. En los años setenta y ochenta del siglo pasado se publicaron materiales de difusión y capacitación de proyectos como la Casa del Museo, los Museos Escolares y los Museos Comunitarios; en la década de los noventa, varios fundadores de estos proyectos publicaron artículos académicos y, en los años recientes, se han desarrollado investigaciones desde una postura crítica ${ }^{3}$.

Aunque reconocemos que es una tarea pendiente documentar a fondo la historia de la Nueva Museología en el país, para los fines de este texto, nos limitaremos a señalar, en el primer apartado, cuatro ejes posibles para el análisis de estas experiencias con el fin de identificar algunas problemáticas inherentes a la dimensión ética de estas prácticas museísticas. En el segundo apartado se presenta la muy reciente propuesta del Programa Nacional de Espacios Comunitarios, programa adscrito a la Coordinación Nacional de Museos y Exposiciones del INAH en 2013, que incorporó la dimensión ética como problemática a discutir en todo proyecto de museología social.

Dicho programa propone la noción de espacio comunitario como posibilidad para acceder a una experiencia museológica, colectiva y horizontal, sin la figura del museo. La apuesta es generar experiencias museológicas a través de exposiciones efímeras o cíclicas en calles, parques, sitios históricos, bodegas, huertos comunitarios y otros lugares, sin que la comunidad deba

\footnotetext{
${ }^{3}$ Especialistas con trayectoria y jóvenes investigadores que no participaron en la génesis de los museos comunitarios entre 1985 y 2000 -varios de ellos, extranjeros estudiando en México-, han elaborado informes y tesis que analizan las aportaciones y las limitaciones de este tipo de museos, principalmente en el modelo oaxaqueño (Alsmann López, Eva Astrid, 2014; Duarte Pérez, Danilo Ivár, 2011; González Cirimele, 2008; González Meza Yadur N. (2012); Hauenschild Andrea, 1988; Melville, Georgia, 2009; Ortiz Maciel, Demián, 2006, 2011; Ortiz Sánchez, 2014; Sepúlveda Schwember, Tomás, 2011).
} 
necesariamente institucionalizar su patrimonio a través de la figura del museo tradicional (INAH, 2014). Es importante señalar que esta "puesta entre paréntesis" de la figura del museo se convierte en necesaria en un contexto en el que el museo ha sido una institución paradigmática del nacionalismo impulsado desde el estado mexicano (Morales Moreno, 1994).

El espacio comunitario puede entenderse como un espacio intersubjetivo para el estudio del proceso museal, asumiendo las consecuencias de una manera corresponsable, de ahí que la dimensión ética sea de interés primordial. Ante la necesidad de documentar estos procesos de interacción social, la tercera sección del documento propone la reflexividad inherente a la investigación de segundo orden como una de las vías posibles para develar los aspectos éticos en la relación sujeto/objeto museal. La riqueza de la experiencia museológica reflexiva propicia que los sujetos no solamente observen objetos museales, sino que despliega la posibilidad de observarse observando la mirada museológica hacia una historia común.

\section{Las experiencias museológicas comunitarias en México}

En México se han impulsado experiencias museológicas que trazan posibilidades de acción colectiva entre actores institucionales y actores de la sociedad civil; el Instituto Nacional de Antropología e Historia, a través de la Coordinación Nacional de Museos y Exposiciones y algunos recintos museísticos como el Centro Comunitarios Ex Convento de Culhuacán, ha contribuido a impulsarlas de forma paralela al surgimiento y desarrollo de la Nueva Museología.

Como se mencionó al inicio, esta sección no contiene un estudio exhaustivo del estado de la cuestión ${ }^{4}$, su propósito es identificar líneas de análisis que develen la dimensión ética. En ese sentido deben señalarse diferencias y afinidades en las tendencias de esta museología comunitaria, los conceptos y las metodologías que orientan las acciones museísticas nunca son neutros, trasminan una visión política de lo cultural.

Finalmente, la cuestión de fondo en la dimensión ética de las experiencias museológicas comunitarias radica en las interacciones entre los grupos de especialistas en diversas disciplinas que trabajan en el campo del patrimonio cultural y los grupos de personas que se engloban bajo el término "comunidad" y que se organizan en comités, juntas vecinales o asociaciones civiles en beneficio del patrimonio cultural. Y, por supuesto, en la diversidad de intereses que impulsan a todos estos actores sociales.

A mediados de los ochenta, coexistían en el INAH dos tendencias; una de ellas, adscrita a la Coordinación Nacional de Museos y Exposiciones, ejemplificada por el Programa para el Desarrollo de la función educativa del museo (PRODEFEM), y en aras de expandir la función educativa del museo, apostaba a la promoción de museos comunitarios, en base al trabajo con una población específica y sus necesidades; la otra tendencia, conocida por el modelo del Programa

\footnotetext{
${ }^{4}$ Sobre las tendencias museológicas en México, ver Morales, 2007 y Pérez Ruiz, 2008.
} 
de Museos Comunitarios de Oaxaca, apostó por la apropiación material y simbólica de los bienes culturales bajo la figura del museo, a través de la organización social tradicional, es decir, la gobernanza por usos y costumbres como la asamblea, el tequio y la organización en comités ciudadanos para gestionar y producir beneficios compartidos.

En otras palabras, la primera tendencia se preguntó sobre la mediación educativa en los procesos museales; la segunda planteó el debate sobre el derecho de usufructo de los bienes culturales. A pesar de sus grandes diferencias conceptuales y metodológicas, ambas convergen en su interés por la figura del museo como espacio en que los objetos museales son puestos en valor a través de la selección y exposición de los objetos 5 .

Hoy en día, la pregunta que nos hacemos en el Programa Nacional de Espacios Comunitarios es acerca de la posibilidad de un "deslizamiento" de la figura del museo para dar paso a experiencias museológicas centradas en las relaciones intersubjetivas de comunidades que indagan sobre la construcción social en de los bienes culturales. Antes de describir los postulados que guían al PNEC, en esta sección presentamos cuatro ejes de análisis que consideramos pertinentes para develar la dimensión ética de los proyectos museológicos comunitarios:
1. Eje de los objetos museales
2. Eje de la autonomía y desarrollo
3. Eje de la interacción humana
4. Eje de la investigación colectiva Eje de los objetos museales: valor patrimonial y valor
documental

La mayoría de los profesionales del campo museístico mexicano considera que su labor cobra sentido en los valores que sostienen la protección del patrimonio; paralelamente -en conjunción con los poderes políticos del momento- estos valores se acercan a una visión esencialista de los bienes culturales. Existe una fuerte tensión entre esta postura y la que valora los bienes culturales como medios para el conocimiento. Este eje analítico, entre lo patrimonial y lo documental, fue señalado por Deloche como el contexto en que subyace el problema del estatus epistemológico de la museología:

Lo sagrado determina el problema de la selección y de la protección (¿es esto digno de ser conservado?, ¿cómo preservarlo) mientras que lo documental define el problema de la presentación (¿qué mostrar?, ¿cómo mostrarlo?). Filosóficamente, aunque haya un campo museal global, de hecho hay dos conceptos del museo, cada uno de los cuales responde a estos dos problemas, a su vez definidos sobre dos planos heterogéneos... (Deloche, 2003, p. 110) [los planos a los que se refiere Deloche son el patrimonial y la documentación visual]

\footnotetext{
${ }^{5}$ En este texto nos adherimos a la definición de lo museal que proponen Bernard Deloche y el ICOFOM (Desvallées \& François, 2009). La idea de lo museal como confrontación del sujeto con la realidad a través de objetos -aportación de pensadores centroeuropeos como Anna Gregorová y Zbyněk Z. Stránský - llegó a México a través de Felipe Lacouture, de quien retomamos la propuesta del estudio museológico como estudio de los postulados, acciones y consecuencias del proceso museal (Lacouture, 1997).
} 
Los proyectos museológicos comunitarios deberían considerar este eje analítico para identificar las posibilidades de que los objetos museales transiten de los postulados de autenticidad y originalidad a las interrogantes sobre el conocimiento del que son portadores los objetos y a las posibilidades comunicativas de su selección y exposición en un espacio. Este eje cuestiona que la museología se practique como una ética o más bien como una moral, ligada a valores absolutos y definitivos (Deloche, 2003, p. 120).

\section{Eje de la autonomía y el desarrollo comunitarios}

Para abordar la cuestión de la autonomía y el desarrollo comunitarios hemos de aquilatar el concepto de "comunidad", concepto que desde las diferentes disciplinas sociales resulta denso y a la vez inaprensible. En este documento usamos la palabra comunidad para referirnos a las relaciones intersubjetivas y dinámicas que permiten la identificación con un "nos-otros", que quizá en el contexto contemporáneo ha perdido su carácter de entidad preexistente y natural (Bauman, 2009), pero no ha borrado la necesidad de un "tiempo experiencial cotidiano" basado en las costumbres (Michel Cuen, 2010).

Es interesante que los diferentes proyectos de museología comunitaria señalen postulados similares que resaltan la autonomía y desarrollo de las comunidades a través de la autogestión. En los programas que hemos elegido como ejemplo de las tendencias existentes, se habla de "...impulsar la creación de museos en forma autogestiva como una alternativa que propone la participación consciente y activa de la población en el rescate y conservación del patrimonio cultural" (INAH, 1989); y también se afirma que el museo comunitario es "...un museo del cual la comunidad se ha apropiado, un museo que considera verdaderamente suyo. Hay hechos concretos que apuntan hacia ello, tales como la propiedad comunitaria del local y de las colecciones. Pero los procesos determinantes para la apropiación son los de la participación y decisión" (Camarena Ocampo, 1994).

La dimensión ética en este eje analítico se relaciona, por un lado con el eje anterior, por el riesgo de juzgar a las propias comunidades con los parámetros de "autenticidad" y "originalidad" que suelen guiar a las acciones museísticas, como si los investigadores externos fueran aptos para valorar si un museo comunitario es o no "auténtico". Por otro lado, sabemos que es posible, a través de la alquimia museográfica, invisibilizar las diferencias, las tensiones y las transformaciones de un grupo social pero... ¿cómo negarse ante la necesidad de una comunidad que -viendo en peligro sus costumbres-, quiere reafirmar de manera vigorosa su identidad a través de un museo? En suma, ¿qué figura de lo museal para qué desarrollo?, ¿cómo se construye la decisión y la participación de cada comunidad, si se expresa a través de la misma figura?

Por un lado, a través de estudios de caso, los especialistas han dado cuenta de los diferentes valores construidos desde los museos comunitarios y por otro lado, en el panorama nacional encontramos que el referente más cercano al de "museo" es la colección de objetos arqueológicos, que son comentados a través del discurso disciplinar de la arqueología y del discurso testimonial. 
Eje de la interacción humana: el rol del promotor, asesor o facilitador

Este eje analítico se refiere a la interrelación entre los actores institucionales y los actores de un grupo social cuando participan en un proyecto museológico comunitario. Por tanto, hace referencia no solamente a las diferencias sociales, culturales y económicas de estos actores, sino también a las desigualdades que fácilmente pueden surgir entre quienes se asumen "expertos" y quienes aceptan "no saber".

Cada proyecto del INAH, operando bajo su propia lógica, ha construido un lugar específico para definir el rol de sus profesionistas. El PRODEFEM en la Ciudad de México, tenía como plataforma la educación popular, por lo tanto, capacitó a maestros normalistas como promotores culturales de museos, considerando que serían aceptados en las comunidades rurales e indígenas y comprenderían mejor las necesidades de la localidad mientras que los integrantes del PRODEFEM se asumían como "capacitadores de capacitadores", supervisores y enlaces. El modelo en Oaxaca, por su parte, tiene como fundamento la tradición indígena del sistema de cargos y la toma de decisiones en asambleas, de manera que impulsó la formación de comités pro-museo para contar con un "sujeto-colectivo" que se responsabilizara del proyecto, ubicando a los actores institucionales como asesores y facilitadores culturales.

En el caso específico de los museos comunitarios en México, habría que analizar con más detalle las pautas de interacción entre las comunidades de investigadores del INAH y los grupos sociales con los que colaboran. La aspiración de que las comunidades sean las protagonistas también suele soslayar la influencia de los asesores científicos y la cuestión de que la figura del museo no es una forma tradicional de representación, representación que al mismo tiempo que visibiliza a una comunidad, establece fronteras respecto a "los otros”. Más que un “...espacio simbólico donde la historia pluriétnica pueda ser reinventada por sus propios poseedores" (Morales Moreno, 2007), los museos comunitarios podrían representar nuevos monólogos regidos por el olvido.

\section{Eje de la investigación colectiva como motor del proceso museal}

Los proyectos museológicos comunitarios, en aras de cumplir sus postulados, han desarrollado diversas estrategias metodológicas. Un aspecto primordial en México recae en los procesos de investigación colectiva, investigación-acción o investigación participativa que nombran esta manera particular de investigar en un diálogo horizontal entre saberes: los saberes de los investigadores profesionales y los saberes de los expertos de la comunidad. La dimensión ética se aprecia en las maneras en que unos y otros colaboran y toman decisiones durante el proceso museal y el grado de compromiso que manifiestan no solamente con la investigación en sí, también con los cambios que se buscan por medio de la investigación.

El quid de este eje analítico tiene que ver con el grado de control de los procesos, pero también con el hecho de que estas comunidades -la "externa" y la "interna", se afectan unas a otras desde sus particulares intereses. A la protección del patrimonio se suman necesidades focalizadas como las necesidades de empleo, la expectativa del turismo cultural o la apropiación de capital simbólico por los líderes políticos; desde el otro lado, encontramos intereses 
personales de investigación, reconocimientos profesionales y cobertura financiera de proyectos.

En síntesis, intentamos señalar que los objetos y los propósitos de la musealización, así como las interacciones humanas en el trabajo colectivo de investigación, pueden ser tópicos útiles para la documentación y análisis de la dimensión ética en los proyectos museológicos comunitarios. Debemos reconocer que aunque los asesores especializados en museos comunitarios remarcan la importancia de los procesos, aún cuando el objetivo sea la operación del museo local, es sintomático que carezcamos de documentación metódica de estos procesos y de las consecuencias.

A continuación, se presenta la propuesta de los Espacios Comunitarios como una de las opciones para la museología comunitaria en México.

\section{El Programa Nacional de Espacios Comunitarios (PNEC)}

EI PNEC empezó a perfilarse en febrero del 2013 bajo la demanda inicial de reactivar un programa de museos comunitarios a nivel nacional. Como primer acercamiento, se realizó un diagnóstico documental sobre museos comunitarios, ejercicio del que derivaron tres planteamientos iniciales:

- Existe una gran diversidad en la operación y conceptualización de los museos comunitarios; algunos se han convertido, con el paso de los años, en museos municipales y también se promueven museos bajo iniciativa municipal o de gobiernos estatales que se autonombran comunitarios.

- En estos recintos se ha registrado un rango amplio de temáticas locales y regionales; sin embargo, al adherirse a las formas discursivas de los museos institucionales, suelen incluir exclusivamente información sobre los objetos exhibidos y dejar en silencio los procesos de saber en torno a ellos.

- Se requieren sistemas de información pormenorizados sobre estas experiencias museológicas. La singularidad de cada museo comunitario se desvanece ante la falta de memoria documental (INAH, 2013a).

Hay que destacar que la revisión bibliográfica sobre museos comunitarios mostró que para los actores -tanto comunitarios como institucionales-, el objetivo final es la creación de un museo. El anclaje a esta figura institucional -que visibiliza las relaciones de fuerza entre los diferentes actores involucrados-, corre el riesgo de reproducir las limitaciones del museo tradicional y enfrenta paradojas como el hecho de que "...nacen legitimándose contra las instituciones culturales, pero están decisivamente apoyados por las mismas" (Burón Díaz, 2012).

En retrospectiva, más que revisar la noción de "museo comunitario", lo que afloró fue el cuestionamiento a la propia figura del museo. Para el PNEC, la palabra museo evoca dos dimensiones que se consideran inherentes al concepto: su espacialidad, entendida como un edificio contenedor, y su temporalidad, que se supone permanente. Esta figura es tan sólida en el imaginario de las diversas 
poblaciones en México que, consciente o inconscientemente, buscan la reproducción del museo tradicional en la comunidad, como si estos elementos -espacio y tiempo-, se juzgaran inalterables en su forma y contenido (INAH, 2014).

Si el concepto "museo" se ha caracterizado bajo dos coordenadas de espacio-tiempo, al parecer inamovibles, entonces se han subordinado las posibilidades de lo museal a un referente histórico particular. Si entre los profesionales de museos también ha permeado el imaginario del museo como una entidad permanente y resguardada entre cuatro muros, como un proceso museal necesariamente instituido, ¿cómo suscribir y renovar los postulados de una Nueva Museología torno a las nociones de territoriopatrimonio-comunidad a partir de un concepto amplio e inclusivo de las experiencias museológicas? ${ }^{6}$

EI PNEC optó por usar el término "espacios" y no "museos", para tener una proyección amplia, que abarque desde museos y centros comunitarios hasta espacios al aire libre, entendidos como experiencias museológicas de diferente duración, ya sean espacios semi-permanentes, temporales, cíclicos o efímeros (INAH, 2014). El punto de partida es el actor más importante en el campo del patrimonio cultural: la gente que lo conserva, lo valora y lo recrea ya sea en la vida diaria o irrumpiendo la cotidianeidad.

Es importante remarcar dos puntos al respecto; primero, que si de derecho $y$ de hecho la museología precede y fundamenta la institución del museo (Deloche, 2003, p. 110-111), el espacio comunitario no está planteando una idea superadora del museo, sino reconociendo lo museal en tanto condición de posibilidad para activar la función documental intuitiva concreta. $Y$ segundo, la necesidad del contexto latinoamericano $-\mathrm{y}$ del mexicano en particular- de desplegar conceptos y prácticas que respondan a las necesidades de información, comunicación y conocimiento de nuestros pueblos.

De acuerdo con Deloche, “...la documentación como instrumento de conocimiento requiere la banalización de los objetos, es decir, la exclusión, la puesta entre paréntesis de su dimensión identitaria y única". Si esto es así, y la sacralización de las colecciones contraviene la dimensión ética del proceso museal, el enfoque de las acciones museísticas se transformaría radicalmente alrededor de comunidades de saber que reflexionan sobre los postulados, acciones y consecuencias del proceso museal:

Es la ética la que le da un sentido a la institución, es decir, la hace comprensible, pues la satisfacción de la necesidad y el ejercicio de la función están limitados por la institución y puestos al servicio de un orden de valores... (Deloche, 2003, p. 119).

El espacio comunitario posibilita la interacción entre las personas de

\footnotetext{
${ }^{6}$ La definición de museo más ampliamente conocida es la que propone el ICOM, que desde 2007 lo define como "... una institución permanente, sin fines de lucro, al servicio de la sociedad y abierta al público, que adquiere, conserva, estudia, expone y difunde el patrimonio material e inmaterial de la humanidad con fines de estudio, educación y recreo". Los espacios comunitarios buscan fines similares y tienen la posibilidad de acompañar procesos sociales vivos, reflejando las transformaciones culturales y reflexionando sobre ellas.
} 
una comunidad y las personas de una institución cultural, educativa o científica, para generar un reconocimiento de los saberes y los vínculos con lugares, objetos y procesos que son considerados patrimonio colectivo, se configuran como un patrimonio, que no es un "a priori esencial".

Desde la construcción del conocimiento no se niega ningún saber, de ahí que el espacio comunitario se concibe como un espacio reflexivo que permite tejer relaciones entre sujetos; estos sujetos pertenecen a diferentes comunidades y sus visiones sobre el patrimonio cultural suelen diferir. Es decir, el conflicto es un elemento que subyace al campo de lo cultural, por ello resulta indispensable visibilizar lo que está en juego y asumir la responsabilidad de la palabra construida en común. Por todo lo anterior, el propósito general del Programa Nacional de Espacios Comunitarios fue enunciado de la siguiente manera:
Coadyuvar con comunidades y otros grupos, que posean el interés y el compromiso de trabajo, para construir espacios comunitarios de reflexión y diálogo bajo un espíritu de corresponsabilidad, en la conservación, protección y difusión de su patrimonio cultural (INAH, 2013b).

Una vez con los referentes sobre la dimensión ética del proceso museal y el planteamiento general del PNEC, la tercera sección propone considerar a la reflexividad procedente de la investigación de segundo orden como una vía de acceso a esa dimensión ética de lo museal y de su práctica.

\section{Dimensión ética y reflexividad en el proceso museal}

En este último apartado, anotamos los postulados iniciales del PNEC, considerando los cuatro ejes analíticos señalados en la primera sección.

- Los valores de los objetos musealizados radican en que son portadores de información, información que nos permiten comprender el saber-hacer del hombre gracias a las diferentes disciplinas que los estudian: arqueología, antropología, etnología, historia, etc. arte, filosofía, sociología, lingüística, comunicología, entre otras.

- La museología, como filosofía de lo museal, puede dar cuenta de los postulados, acciones y consecuencias de los procesos museales. Discierne el poder de los objetos museales como elementos de cohesión identitaria y también acerca de su capacidad para conservar y transmitir formas culturales.

- Los Espacios Comunitarios posibilitan el diálogo entre comunidades para generar nuevos conocimientos a partir de los objetos musealizados. Estos conocimientos son aportaciones a las disciplinas científicas y al saber de las propias comunidades. A ello se suma la reflexión sobre la propia experiencia museológica para que emerjan lospostulados que guían las acciones museales colectivas.

- La interacción es entendida como la "simultaneidad de escuchar y comprender al otro, mientras el otro nos escucha y nos comprende" (Michel Cuen, 2010). Es decir, hay reciprocidad entre las partes que intervienen, un 
reconocimiento de cómo se afectan mutuamente los investigadores profesionales y los expertos de la comunidad en los proyectos museológicos comunitarios.

EI PNEC sostiene que la aportación del INAH radica en sus saberes especializados. La historia, la antropología, la lingüística, la etnología, la conservación y la arqueología han generado acervos de conocimientos sistemáticos, cuestionados y reformulados de manera constante. Por otro lado, la museología es un campo de conocimiento en construcción pero su acción es quizá la cara del INAH más conocida para la sociedad en general. Si toda exposición museal es una mirada de segundo orden sobre lo real, las capacidades de reflexión, imaginación y comunicación que conllevan posibilitan verdaderos diálogos.

Por ello creemos que la investigación colectiva es la herramienta privilegiada para construir relaciones y para generar otros mundos posibles. La cuestión está en que cada proyecto de investigación del Instituto repercute en la conservación y la renovación de las formas culturales de las comunidades, muchas veces con una retroalimentación negativa, porque se actúa partiendo de que existe una manera correcta de cuidar el patrimonio, la propia.

El tema de las consecuencias que derivan de los proyectos de investigación del ámbito patrimonial desarrollados por las instituciones excede los propósitos de este texto, pero debemos mencionar que las repercusiones son múltiples y complejas: expropiación de territorios para declararlos sitios arqueológicos, revaloración de tradiciones por el interés que despiertan en otros, la oportunidad de generar beneficios económicos, el saberse objeto de estudio, entre muchas otras.

En realidad, existen muchas formas de conservar y comunicar las formas culturales, por eso el PNEC apunta a revisar la relación entre el Instituto y los grupos interesados en la salvaguarda y difusión del conocimiento del patrimonio a través de la investigación colectiva. Cuando el experto logra identificar los procesos de conservación, transmisión y valoración de lo patrimonial en los otros actores sociales, se inicia una revisión de sus propios saberes, es decir, se provoca una revisión de su propia praxis. Cuando los actores sociales "neófitos" participan de manera propositiva con los expertos, pueden obtener informaciones que contradigan sus creencias y anclajes simbólicos, lo que también lleva a un proceso de reflexibilidad. Lograr esto es uno de los retos del Instituto Nacional de Antropología e Historia durante el siglo XXI.

Si los sistemas de conocimiento son "el orden subjetivo de los sistemas sociales...la perspectiva de representación-creación de todo lo que aparece en el mundo social, de todo lo que ha aparecido y de todo lo que puede aparecer" (Galindo, 2003), entonces la construcción colectiva del conocimiento entre comunidades heterogéneas que se alternan en el rol de "expertos", en los papeles de "el que habla" y de "el que escucha", haría posible reconfigurar los postulados sobre los usos sociales del patrimonio cultural.

Las consecuencias que derivan de las acciones museológicas tienen que ver con lo que señaló Deloche (2003) sobre "construir históricamente una sociedad basada en una utilización reflexiva de las imágenes", imágenes que tienen que ver con uno mismo y su 
medio, pero también -y de manera ineludible-, con las imágenes de los otros, es una cuestión de orden ético.

Ahora bien, la Cibercultura no puede limitarse a la noción que propone Deloche como "la cultura creada por el mundo de las nuevas imágenes", pues resultaría limitada ante la gama de experiencias museológicas posibles. Ante este reto, preferimos retomar el concepto de cibercultura desde una visión sistémica, anclada en la cultura de investigación, que nos conduzca a procesos de reflexividad:

La diferencia específica del sentido de la cultura y la cibercultura es la reflexividad, la cultura busca sistematizar conocimiento y competencia práctica en la acción para ciertos fines sociales. La cibercultura busca lo mismo, pero con el énfasis en la mirada en los componentes de orden y organización, no sólo busca conocimiento y competencia, sino la estructura y el orden que los sustenta. La cibercultura es una metacultura que incluye a la cultura y la reorganiza. (Galindo, 2003).

En otras palabras, la comunicación entre comunidades, el espacio comunitario intersubjetivo -cuyo poder descansa en su heterogeneidad-, posibilita la acción reflexiva, esa doble dimensión en juego que busca el conocimiento de cierto objeto y simultáneamente reordena sus visiones sobre los pasos constructivos del objeto: "hacer lo mismo que hacemos todos los días pero mirándonos y decidiendo si queremos seguir así o modificar nuestras prácticas y ecologías" (Galindo, 2003).

La riqueza de la experiencia museológica reflexiva propicia que los sujetos no solamente observen objetos museales, sino que observen también el proceso de musealización de esos objetos, en suma, la posibilidad de observarse observando una mirada museológica que desde la operación reflexiva- es comunitaria.

\section{Referencias}

Burón Díaz, M. (2012). Los museos comunitarios en el proceso de renovación museológica, Revista de Indias, 254 (LXXXII), 177212.

Bauman, Z. (2009). Comunidad. En busca de seguridad en un mundo hostil. Madrid, Siglo XXI.

Camarena Ocampo, C., Morales, T., \& Valeriano, C. (1994). Pasos para crear un museo comunitario. México: CNCA/INAH/DGCP.

Deloche, B. (2003). El museo virtual. Hacia una nueva ética de las imágenes. Gijón: Trea.

Galindo Cáceres, L. J. (2003). Cibercultura de la investigación. Intersubjetividad y producción de conocimiento. Recuperado de http://www.ugr.es/u-veracruzana/comunicaciones _archivos/a3-mxGalindo\%20UV-final.pdf

Desvallées, A., \& François M. (Dirs.). (2009). ICOFOM Study Series:

Museology. Back to the Basics, 38.

INAH [Instituto Nacional de Antropología e Historia]. (1989). Departamento de servicios educativos museos escolares y comunitarios. Memoria 1983- 1988. México: CNME-INAH.

INAH [Instituto Nacional de Antropología e Historia] (2013a). Programa Nacional de Espacios Comunitarios. Diagnóstico documental de museos comunitarios. Junio 2013. México: CNME-INAH.

INAH [Instituto Nacional de Antropología e Historia] (2013b). Programa Nacional de Espacios Comunitarios. Proyecto. Julio 2013. México: CNME-INAH.

INAH [Instituto Nacional de Antropología e Historia] (2014). Programa Nacional de Espacios Comunitarios. Folleto. 
Lacouture Fornelli, F. (1989). La Nueva Museología. Conceptos básicos y declaraciones. Revista de la Escuela Nacional de Artes Plásticas, 8 (2), $19-28$.

Lacouture Fornelli, F. (1997). Museología, estudio científico del proceso museal. Propuesta de una definición sistemática. Gaceta de museos, 8, 5-9.

Michel Cuen, G. (2010) Cultura: tiempo y complejidad: la experiencia reflexiva. México: Conaculta.

Morales Moreno, L. G. (1994). Orígenes de la museología mexicana: fuentes para el estudio histórico del Museo Nacional. 1780-1940. México: UIA.

Morales Moreno, L. G. (2007). Museológicas. Problemas y vertientes de investigación en México. Relaciones, 111 (XXVIII), 31-66.

Pérez-Ruiz, M. L. (2008) La museología participativa: ¿tercera vertiente de la museología mexicana? Cuicuilco (15) 44. Septiembre-diciembre, 87 110.

Alsmann López, E. A. (2014). Participación, democratización del patrimonio e identidad en el museo comunitario de la antigua estación ferroviaria de Teocelo, Veracruz. México: Universidad Veracruzana. Tesis de maestría en estudios de la cultura y comunicación.

Hauenschild Andrea. (1988). Claims and Realty of New Museology: Case Studies in Canada, the United States and Mexico. Disertación doctoral, publicada originalmente por el ICOM en alemán. Consultado en marzo de 2015. Recuperado de http://museumstudies.si.edu/claims2000.htm.

Duarte Pérez, D. I. (2011). "Se deja estar y olvidar": La apropiación comunitaria del museo en los estados de Oaxaca y Nayarit. México: ENCRYM. Tesis de maestría en museología.

González Cirimele, L. (2008). Funcionamiento del poder y del saber en el discurso/texto museográfico comunitario. Cuicuilco (15) 44. Septiembre-diciembre. 135-159

González Meza, Y. N. (2012). Diversidad cultural en los museos comunitarios de México. México: Universidad Veracruzana. Tesis de maestría en estudios de la cultura y comunicación.

Melville, G. (2009). Museografía con una comunidad transnacional. Revista Alteridades, (19) 37. Enero-junio. 57-67.

Ortiz Maciel, D. (2006). El Ecomuseo: un espacio comunitario para recordar, conocer y reinventar. Análisis y propuestas para su posible aplicación en Piedra Labrada, Veracruz. México: Universidad Veracruzana. Trabajo recepcional de licenciatura en antropología histórica.

--- (2011). Museos, territorio y patrimonio in situ: trabajo de campo en el Centro de Visitantes Schuk Toak y el Ecomuseo Tehuelibampo, Sonora. Intervención. Revista Internacional de Conservación, Restauración y Museología (2) 4.Julio-diciembre. 48-55.

Ortiz Sánchez, M. E. (2014). Los museos comunitarios como dispositivos de reproducción y cambio cultural; el caso de los lacandones en Nahá, Chiapas. Discurso Visual. Revista electrónica 34. México: INBA/ Cenidiap. Julio-diciembre.

Sepúlveda Schwember, T. (2011). Museología y comunalidad. Una aproximación al estudio de los museos comunitarios de Oaxaca. Barcelona: Universitat de Barcelona. Trabajo final del master en gestión del patrimonio cultural. 


\section{Resumen}

El artículo examina la dimensión ética de las experiencias museológicas que ha impulsado el Instituto Nacional de Antropología e Historia en México desde el enfoque de la Nueva Museología. El texto está integrado por tres apartados; en el primer apartado, se identifican algunas de las problemáticas inherentes a la dimensión ética de dichas experiencias; el segundo apartado presenta al Programa Nacional de Espacios Comunitarios que plantea la noción de espacio comunitario como experiencia museológica colectiva -sin la figura del museo-, y tomando en cuenta la dimensión ética del proceso museal. Por último, se propone a la reflexividad generada desde la investigación de segundo orden como una de las vías posibles para develar los aspectos éticos en la relación el sujeto y el objeto museal.

Palabras clave: museología comunitaria en México, proceso museal, dimensión ética, reflexividad

\section{Abstract}

\section{Ethics and Reflexivity}

Community Museum Experiences in Mexico

This article examines the ethical dimensions of community museum experiences within Mexico's National Institute of Anthropology and History since the advent of New Museology. In it, three ideas are explored. First I try to identify some of the inherent problems and ethical dimensions of these experiences; then, in the second section, I present the notion of "community space" as an entity in which it is possible to foster community experiences within the logic of the museum process (as proposed by Mexican museologist Felipe Lacouture) and its ethical dimensions, but doing it outside of the proper museum space. Finally it is proposed that secondary research will aim to reveal ethical issues in the visitor - object relationships, across reflexivity exercises generated by second order research.

Key words: Community Museology in México; museum process; ethical dimension, reflexivity 